\title{
Hypoxia in mangroves: occurrence and impact on valuable tropical fish habitat
}

\author{
Alexia Dubuc $^{1,2}$, Ronald Baker ${ }^{3}$, Cyril Marchand ${ }^{4}$, Nathan J. Waltham ${ }^{1,2}$, and Marcus Sheaves ${ }^{1,2}$ \\ ${ }^{1}$ College of Science and Engineering, James Cook University, Townsville, 4810, Australia \\ ${ }^{2}$ TropWATER, Townsville, 4810, Australia \\ ${ }^{3}$ Dauphin Island Sea Lab, Department of Marine Sciences, University of South Alabama, Alabama 36528, USA \\ ${ }^{4}$ Institute of Exact and Applied Sciences, University of New Caledonia, Nouméa, 98800, New Caledonia
}

Correspondence: Alexia Dubuc (alexia.dubuc1@my.jcu.edu.au)

Received: 8 May 2019 - Discussion started: 20 May 2019

Revised: 5 September 2019 - Accepted: 12 September 2019 - Published: 15 October 2019

\begin{abstract}
Intertidal mangrove forests are harsh environments that can naturally experience hypoxia in association with low tide. However, we know relatively little about dissolved oxygen (DO) fluctuations and DO-induced responses by fish, although DO is a fundamental water quality parameter. This study examines DO as a potential factor regulating the utilisation of intertidal mangrove forests by fish and consequently their widely recognised feeding, refuge and nursery values. We deployed underwater video cameras, coupled with DO and depth loggers, in a mangrove forest to record changes in fish assemblages in response to tidal variations in DO and other associated environmental parameters. Our results indicate that DO underwent extreme tidal fluctuations, reaching levels as low as $14 \%$ saturation. As DO was identified as a significant factor for explaining variability in fish assemblage composition, we further investigated fish responses to DO fluctuations. Higher taxonomic richness and frequencies of occurrence were observed once DO reached $70 \%-$ $80 \%$ saturation. More detailed examination revealed speciesspecific responses. Three distinct patterns of mangrove utilisation in response to DO were identified, driven by apparent taxa's behavioural DO avoidance thresholds. Most taxa did not display any behavioural avoidance, including presence at the lowest DO levels, while other taxa were not observed either below $50 \%-60 \%$ saturation or below $70 \%-80 \%$ saturation. This implies that tidal migrations, often observed in intertidal environments, could be the result of differential DO tolerances and are not simply initiated by changes in water depth. Taxa remaining in the mangrove forest even at low DO were on average more frequently observed than
\end{abstract}

the other taxa and were mostly species commonly associated with mangrove habitats. This suggests that being adapted to withstand low DO might be an important condition for using mangrove habitats extensively. The need of being tolerant to low DO could constrain fish utilisation and explain the relatively low species richness often observed in other intertidal mangrove forests.

\section{Introduction}

Mangrove forests are recognised as important habitats for fish (Robertson and Duke, 1990; Nagelkerken et al., 2002, 2008). However, their commonly recognised feeding, refuge and nursery value has been shown to be heterogenous and influenced by local environmental factors influencing mangrove forests' accessibility and suitability (Faunce and Serafy, 2006; Bradley et al., 2019). Mangroves can be challenging habitats, especially in regions where they are subjected to tide (Unsworth et al., 2007; Olds et al., 2012), as tidal variation generates a range of constraints. Mangrove forests generally become only accessible for short periods while flooded at high tide, and the decrease in water depth as the tide ebbs leads to eventual drainage of the forest (Sheaves, 2005; Baker et al., 2015). Tidal variation also induces short-term changes in environmental conditions, such as salinity, temperature, water depth, turbidity, light and dissolved oxygen (DO), that can lead to a temporarily unsuitable habitat for fish utilisation (Davis, 1988; Rountree and Able, 2007; Brady and Targett, 2013; Dubuc et al., 2017; Mattone and Sheaves, 2017). 
Several studies have demonstrated that fish undertake regular migrations in intertidal mangrove forests. Migration patterns have been shown to be species-specific and influenced by tide (Laroche et al., 1997; Krumme, 2004; Ellis and Bell, 2008; Meynecke et al., 2008; Sheaves et al., 2016; Dubuc et al., 2019). Tidal migrations indicate that fish respond to one or several factors varying with tide. However, there is still uncertainty on what environmental factors induce these tidal migrations. The factors driving these species-specific tidal migrations could be changing water depth (Bretsch and Allen, 2006; Ellis and Bell, 2008; Reis-Filho et al., 2016) or alternatively the result of active avoidance of adverse changes in water quality.

A key factor determining water quality and that can change drastically across tide is DO. DO is crucial for all aerobic organisms, including fish (Driedzic and Hochachka, 1978; Falkowski and Raven, 1997). However, DO availability varies extremely over the tidal and diel cycle in mangrove habitats, reaching levels that can lead to physiological stress (Knight et al., 2013; Dubuc et al., 2017; Gedan et al., 2017; Mattone and Sheaves, 2017). Consequently, it is likely that some fish species respond to changes in DO by undertaking tidal migrations or by avoiding mangrove forests permanently to prevent the adverse effects following exposure to low DO. Despite the importance of DO and its extreme variability in shallow-water environments, our understanding on how DO fluctuations shape patterns of fish utilisation on a tidal and diel scale is limited (Davis, 1988; Smith and Able, 2003; Rountree and Able, 2007).

DO is maybe the most complex and variable parameter to study, as it is influenced by multiple interacting biotic and abiotic parameters at a range of spatial and temporal scales (Buffoni and Cappelletti, 1999; Diaz and Rosenberg, 2008; Nezlin et al., 2009). The main factor responsible for DO fluctuations is the autotrophic cycle, with photosynthesis occurring during daylight hours and respiration during nighttime hour, creating a diel cycle in DO. Another important parameter to consider, especially in intertidal environments, is tide, as it is responsible for many physical and chemical changes susceptible to impact oxygen cycle. If these two factors are considered, DO can be partially predicted, with the lowest DO levels occurring at night or dawn at low tide, following nighttime respiration, while maximum levels are recorded in the afternoon at high tide, following autotrophic production (Kenney et al., 1988; Mazda et al., 1990; D'Avanzo and Kremer, 1994; Tyler et al., 2009). This diel pattern gives part of the answer of when fish could be able to use mangrove habitats without being exposed to high risks of low DO. However, fish species have developed physiological and behavioural adaptation strategies (Kramer, 1987; Breitburg, 1994; Diaz and Rosenberg, 1995), leading to species-specific hypoxia tolerances (Vaquer-Sunyer and Duarte, 2008). Consequently, these adaptations could result in species-specific tidal migrations, as species highly tolerant to hypoxia would be adapted to use more often and remain longer in mangrove forests compared to other less-tolerant species that would be restricted to access mangrove forests at higher DO levels.

Although it is known that mangrove forests experience natural low DO in some locations (Knight et al., 2013; Mattone and Sheaves, 2017), it is unknown how general this phenomenon is and what the potential consequences on fish populations are. Understanding DO dynamics and the impacts on fish utilisation and value of highly productive habitats such as mangroves is crucial, especially in the context of global ocean deoxygenation (Diaz and Rosenberg, 2008; Breitburg et al., 2018). Ocean deoxygenation is mainly due to the increase in human activities along the coastlines during the past 50 years (Vaquer-Sunyer and Duarte, 2008), implying that mangrove ecosystems are especially prone to experiencing anthropogenic deoxygenation due to their location along the coasts. By addressing the gaps of knowledge around hypoxia in mangrove forests, managers would be in a stronger position to implement adequate action plans to limit the impact of hypoxia that is predicted to worsen in the coming years (Breitburg et al., 2018).

This study examines the impact of DO fluctuations on the utilisation of mangrove forests by fish in a mangrove-coralreef seascape in the Indo-West Pacific (IWP). We assessed how fish utilisation changes across tidally varying DO levels, and we determined the relative importance of DO, depth, lunar phase (neap vs spring), location within the mangrove forest (edge vs in forest), time of day and tide direction (flooding vs ebbing) in explaining variations in fish assemblages. To address this aim, we used unbaited underwater video cameras, simultaneously deployed at dawn and mid-afternoon on the edge and $5 \mathrm{~m}$ inside a mangrove forest, coupled with high-frequency DO and depth loggers. The study site was located in an IWP mangrove-coral-reef seascape experiencing a microtidal regime.

\section{Materials and methods}

\subsection{Study site}

The study was conducted in a semi-enclosed lagoon $(1.2 \mathrm{~km}$ long, $60 \mathrm{~m}$ wide and $1-2 \mathrm{~m}$ depth) located in Bouraké, South Province, New Caledonia $\left(21^{\circ} 56.971 \mathrm{~S}\right.$, $165^{\circ} 59.481 \mathrm{E}$; Fig. 1). The system comprises a $2.5 \mathrm{~km}^{2}$ mangrove forest dominated by Rhizophora stylosa on the seaward edge and Avicennia marina on the landward margin. A channel (20-70 m wide, 2-6 m depth and $700 \mathrm{~m}$ long) bisects the mangrove forest and connects the semi-enclosed lagoon to the coastal waters of Pritzbuer Bay $\left(\sim 20 \mathrm{~km}^{2}\right)$. The channel comprises two sheltered inlets (approximately $0.01 \mathrm{~km}^{2}$ each) and a shallow (1-2 m depth) coral-reef platform that extends from the middle of the channel to the edge of the mangrove forest. New Caledonia is an archipelago located in the South-Western Pacific, around $1500 \mathrm{~km}$ east of Australia. It is characterised by a semi-arid to tropical climate, 
with an annual total rainfall of $1000 \mathrm{~mm}$ and a mixed semidiurnal microtidal regime (maximum $1.8 \mathrm{~m}$ tidal range). The study system receives little freshwater inflow, with no defined drainages.

\subsection{Data collection}

Nine sites were selected on an inland-offshore gradient along the channel (Fig. 1). Sites 1 to 8 were four paired sites, with odd site numbers located on the mangrove forest edge (defined as the boundary between mangrove prop roots and bare substrate) and even site numbers located $5 \mathrm{~m}$ inside the mangrove forest. Site 9 was located on the edge of scattered mangrove trees growing on the reef platform of the innermost inlet and was considered to be an edge site.

Fish assemblages were examined at the sites using unbaited underwater video cameras (UVCs). UVCs were deployed at dawn until the battery was discharged (around $2.5 \mathrm{~h})$ and again in the mid-afternoon, during neap (21 to 23 February 2017) and spring tides (28 February to 1 March 2017), simultaneously at the nine sites. This sampling design was applied to capture fish assemblages as close as possible to the expected lowest daily DO levels (dawn) and the expected highest DO levels (mid-afternoon; Dubuc et al., 2017). Cameras were positioned around $7 \mathrm{~cm}$ above the substrate, facing towards the channel. A marker was placed $0.5 \mathrm{~m}$ in front of the camera lens as a visibility indicator to ensure that all videos had a minimum visibility of $0.5 \mathrm{~m}$. Visibility was relatively consistent during the sampling period, and fish could be identified confidently up to approximately $2 \mathrm{~m}$ from the UVCs in all videos.

Over this study, we examined the effects of tidal factors (depth, lunar phase - spring vs. neap - and tide direction - flooding vs. ebbing) related to habitat accessibility; DO, temperature and salinity related to habitat suitability; and two different components of the mangrove forest (edge and in forest) related to the nature of mangrove habitats. Between 21 February and 1 March 2017 , near-bottom $(\sim 5 \mathrm{~cm}$ above the sediment) DO (\% saturation) and water temperature $\left({ }^{\circ} \mathrm{C}\right)$ were measured every $15 \mathrm{~min}$ at each site using calibrated multi-parameter loggers (YSI ProODO model - accuracy $\pm 1 \%$ saturation). A depth logger (In-Situ Inc. Rugged TROLL 100 model) was coupled with each multi-parameter logger to measure water depth $(\mathrm{cm})$ every $15 \mathrm{~min}$. Salinity was measured every $15 \mathrm{~min}$ from 21 to 23 February and between 28 February and 1 March 2017 using another multiparameter logger (YSI $6920 \mathrm{~V} 2-2$ ) positioned at site 5. The tidal range was obtained from the SHOM website (SHOM, 2017).

\subsection{Data extraction from videos}

Methodological details to extract data from the videos are reported in Dubuc et al. (2019). Briefly, as considerable time is required to process videos, we subsampled the ac- quired recordings. One neap tide and one spring tide sampling were randomly selected for processing. Five sites from the second neap tide and spring tide sampling were also processed, so one randomly selected replicate on the reef platform (site 9) and two replicates of randomly selected paired sites, not located on the reef platform, were acquired (sites 5 8). Videos were viewed using the VideoLAN Client media player (VLC) and subdivided into 5 min intervals to follow the temporal variations in fish assemblages. All taxa observed in each $5 \mathrm{~min}$ interval were identified and recorded. Only presence or absence data were recorded to avoid biases induced by count data when using UVCs (Sheaves et al., 2016). Fish were identified to the lowest possible taxonomic level, with all fish identifications validated by two additional experts. For each 5 min interval video, information about depth, DO, time of day, lunar phase (neap vs spring), habitat (edge vs in forest) and tide direction (flooding vs ebbing) was recorded.

\subsection{Data analysis}

To graphically investigate temporal dynamics of DO on the edge and in forest, and covariance with depth and temperature, cubic spline smoothers were fitted to the three time series using R. DO residuals were graphically added to emphasise extreme DO levels. Kendall's correlation test (as DO did not follow a normal distribution) was used to determine whether patterns of change in DO were significantly correlated between edge and in-forest sites. Cumulative DO frequency curves (Dubuc et al., 2017) were plotted for each site to highlight differences in spatial and temporal dynamics.

Following the methodology described in Dubuc et al. (2019), an index depending on observation per unit effort (OPUE) was used to calculate frequencies of occurrence for each taxa (the total number of 5 min intervals in which a taxon was observed in one sample unit was divided by the total number of $5 \mathrm{~min}$ intervals recorded for the same sample unit). We acknowledge the existence of a non-independence issue created by subsampling videos in 5 min intervals. Indeed, this can potentially lead to the count of the same individual fish in sequential time windows. However, the objective here was to characterise environmental conditions suitable for the utilisation of mangrove habitats through time by different taxa. Therefore, we assumed that if an individual of a taxon was present (no matter if it was the same individual or another one to any recorded in previous 5 min intervals), then conditions were suitable. Frequencies of occurrence were first calculated per site. Only taxa with a frequency of occurrence $\geq 0.05$ on at least one site were retained for analyses (hereafter referred to as "common taxa").

We hypothesised that DO is an important factor in explaining the presence of fish taxa. To test this hypothesis, a random forest (RF) model (Breiman, 2001) was used to quantify the relative importance of DO and the other measured environmental factors and identify how well the combination of the 


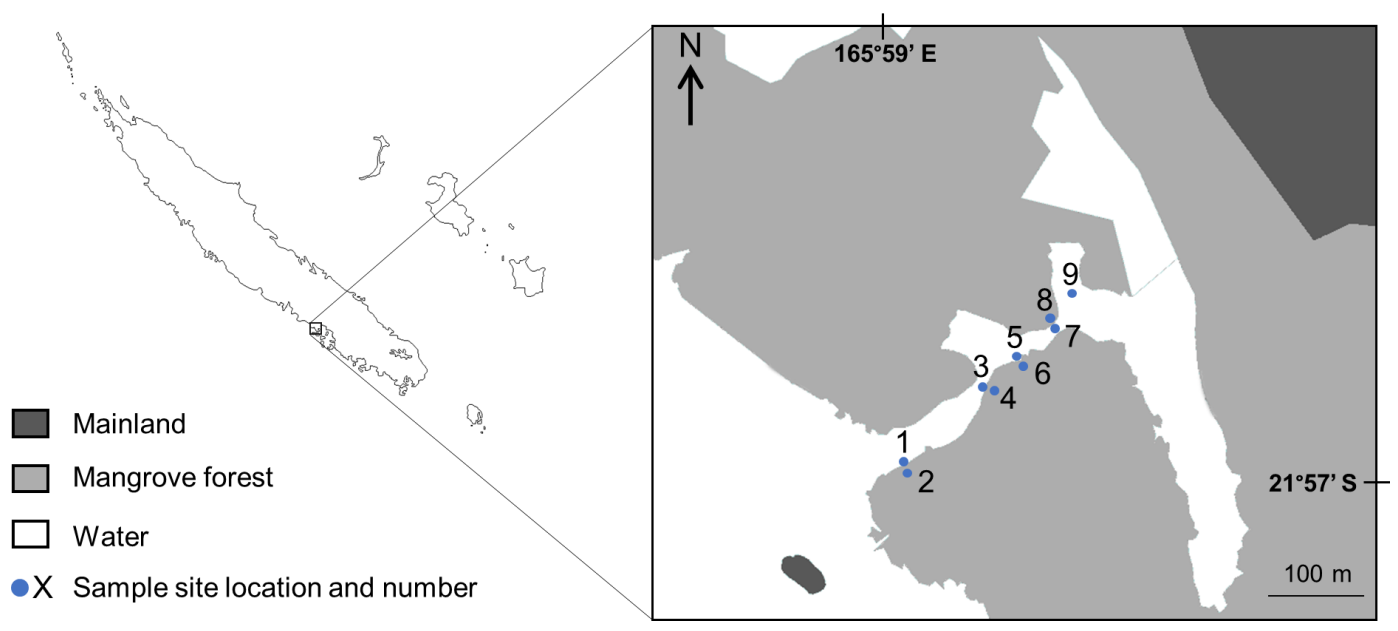

Figure 1. Map of the study system in Bouraké, South Province, New Caledonia. The nine study sites sampled from 21 February to 1 March 2017 are indicated by their corresponding numbers. Light grey areas represent mangrove forest, dark grey areas represent mainland and white areas represent water.

selected environmental factors predicted fish taxonomic richness. This machine learning algorithm permits analysis of data that do not meet the requirements of normality and homoscedasticity required for approaches such as general linear models and include repeated measurements (Mercier et al., 2011). The taxonomic richness was determined for each 5 min interval recorded (a total of 1434 intervals of $5 \mathrm{~min}$ ). The dataset was then split into two to obtain a training dataset (875 intervals of 5 min obtained from the 2 entire sampling days processed) to build the RF model and a test dataset (559 intervals of $5 \mathrm{~min}$ obtained from the five replicate sites processed) to test the robustness of the model at predicting taxonomic richness. The RF model, consisting of 1000 regression trees generated using two predictors at each split (default value), was created to predict taxonomic richness, with "Habitat" (edge vs in forest), "Depth", "DO", "Lunar phase" (neap vs spring), "Time of day" (morning vs afternoon) and "Tide direction" (flooding vs ebbing) as predictors. The outof-bag error estimate, corresponding to a measure of the prediction error of the random forest, was used to validate the model. The increased mean-square error (MSE) was calculated to determine the variable importance in predicting taxonomic richness. The model was then run on the test dataset to generate a confusion matrix. From the confusion matrix, the percentage of cases when the model was able to predict the exact taxonomic richness observed was calculated as well as the percentage of cases where the model was able to predict the taxonomic richness observed at \pm 1 taxon. All RF model-related analyses were conducted using the "randomForest" package in R (Breiman, 2001). As a RF model is built from many classification trees, it is not accurate to draw a single tree from this model. Therefore, a univariate classification tree analysis was carried out on the training dataset with the same variables as the RF, and the tree obtained from this analysis was used to visually interpret the RF model. The univariate classification tree analysis was performed using the package "party" in R (Hothorn et al., 2010).

After quantifying the importance of DO, the goal was to understand when fish initiated responses to DO. Each 5 min video interval was allocated to a DO percentage saturation class in $10 \%$ intervals (from $30 \%-40 \%$ saturation to $100 \%-110 \%$ saturation) according to the DO level recorded. The frequency of occurrence of each common taxon per class of DO was then calculated to investigate whether intensity of utilisation varied in response to DO. A general additive mixed model (GAMM) was built with $\log _{10}(X+1)$-transformed frequencies of occurrence of each common taxon as the response variable, "DO" as a smooth term and "Habitat" (edge vs. in forest) as a parametric term, using a Gaussian distribution and an identity link function. The model was built using the package "mgcv" in R (Wood, 2007). Frequencies were $\log _{10}(X+1)$-transformed to reduce the impact of extreme values and improve visualisation. The frequencies of occurrence of each common taxon across DO were also plotted individually using a loess curve. Patterns were then investigated individually and visually grouped by similarity of mangrove utilisation in response to DO. No grouping was imposed, and visualisation of the data identified three common patterns of mangrove utilisation across DO among all common taxa. These three patterns were based on distinct preferences for DO with taxa recorded from $30 \%$ to $110 \%$ saturation, taxa recorded from $50 \%$ to $110 \%$ saturation and taxa recorded from $70 \%$ to $110 \%$ saturation.

Taxa observed in mangrove habitats even at low DO (from $30 \%$ to $110 \%$ saturation) may indicate that these fish are well adapted to using mangrove habitats extensively and therefore expected to be observed more frequently than the other taxa. To test this hypothesis, overall frequencies of oc- 
currence were calculated for each common taxon by dividing the total number of 5 min intervals in which a taxon was observed by the total number of $5 \mathrm{~min}$ intervals recorded during the study at the DO range corresponding to that taxon's assigned pattern of utilisation $(30 \%-110 \%$ saturation; $50 \%-$ $110 \%$ saturation; $70 \%-110 \%$ saturation). Following this methodology allows for calculating frequencies of occurrence according to the effective sample size; it therefore overcomes the unbalanced sampling effort, as species recorded across the entire range of DO would automatically be more frequent than species only recorded from $70 \%$ to $110 \%$ saturation, since it represents a smaller proportion of the sample size. Species-specific overall frequencies of occurrence were then plotted by the type of patterns of utilisation assigned using boxplots. To test for differences in overall frequencies of occurrence among the different types of patterns of utilisation, a Kruskal-Wallis test, followed by a post hoc Dunn test, was performed (data did not follow a normal distribution).

\section{Results}

All relevant data are freely available online on the Tropical Data Hub repository: https://doi.org/10.25903/ $5 \mathrm{~cd} 4 \mathrm{~d} 312 \mathrm{cbcfb}$ (Dubuc, 2019).

DO was highly variable at the mangrove study sites in Bouraké (Fig. 2). DO reached levels as low as $14 \%$ saturation at night low-neap tides during the entire logging period and as low as $35 \%$ saturation during the morning hours that coincided with low spring tides while UVCs were deployed (Fig. 2; Table 1). DO closely followed the diel and tidal cycles, with daily maximum levels recorded during the afternoon high tide and minimum levels recorded during the night or early morning low tide. Temperatures followed a typical diel cycle, peaking during the late afternoon and declining at night, reaching minimum levels in the early morning hours. Salinity was relatively constant during the study, ranging between 32.1 and 34.9.

Temporal dynamics in DO were significantly correlated between in-forest and edge habitats $(p<0.0001 ; r=0.95$; Fig. 2; Fig. A1 in Appendix). DO minima and maxima were also similar between edge and in-forest sites (Table 1). Most DO levels were between $70 \%$ and $80 \%$ saturation; nevertheless, DO levels were equal to or below $50 \%$ saturation (adopted threshold for hypoxia; Breitburg, 2002; Dubuc et al., 2017) for around $11 \%$ of the time inside the forest and $21 \%$ on the edge (Fig. 3). Mean and minimum DO levels were lower during neap tides than spring tides for both edge and in-forest sites (Table 1). The duration of low DO tended to increase with distance from the mouth of the channel, with DO at or below $50 \%$ saturation $4 \%$ of the time at the inforest site closest to the channel entrance (site 2) and $14 \%$ of the time at the in-forest site furthest from the channel entrance (site 8; Fig. 3).
Fifty-six video deployments were processed (totalling more than $118 \mathrm{~h}$ of video); 72 taxa from 29 families were recorded, with 36 common taxa (frequency of occurrence $\geq 0.05$ ) retained for further statistical analyses (Table 2). The full list of taxa identified is provided in Table A1. Among the 36 common taxa identified, only 23 taxa were recorded in forest, while on the edge 34 were recorded.

We used a RF model to assess the relative importance of several environmental factors in determining taxonomic richness. The robustness of the model in predicting taxonomic richness at this location was also tested. The RF model consisted of 875 intervals of $5 \mathrm{~min}$ and six independent environmental factors. It explained $50.2 \%$ of the total variance in taxonomic richness. "Depth" was the most important factor for predicting taxonomic richness, with its exclusion from the model increasing the MSE by more than $61 \%$ (Fig. 4a). "Lunar phase", "DO" and "Habitat" were also important predictors of taxonomic richness (between $45 \%$ and $55 \%$ increase in MSE). "Time of day" and "Tide direction" were of less importance but still accounted for an increase in MSE of more than $35 \%$. The RF model successfully predicted the exact taxonomic richness observed on the replicate sites for $23 \%$ of the $5 \mathrm{~min}$ intervals recorded and for $60 \%$ of them at \pm 1 taxon (Table S1 in the Supplement). DO and depth were highly correlated, which can potentially impact the RF prediction of variable importance, although there is no agreement on what the effects of multicollinearity are (Gregorutti et al., 2017). However, RF is a very robust method, and in this study, considering the large dataset used with only few predictors that are all relevant to explaining fish assemblages, we believe that overfitting is not an issue. Nevertheless, a RF model was built only with "Depth" and then only with "DO" to test for the effect of multicollinearity on their relative importance. In both cases, the total variability explained by the model was much lower $(33.42 \%$ with only "Depth" included and $26.36 \%$ with only "DO" included) than when "Depth" and "DO" were both included (50.22\%). The univariate tree corroborated the results of the RF in terms of variable importance and proved to be an effective way of getting a visual interpretation of the RF (Fig. 4b). The taxonomic richness was the lowest at in-forest sites and on the edge during spring tides. Conversely, taxonomic richness was the highest when water depth was the deepest during neap tides and when DO was greater than $83 \%$ saturation.

The RF model showed that DO was an important factor in explaining variations in taxonomic richness. We therefore further investigated fish responses to DO; $\log _{10}$-transformed frequencies of occurrence of all taxa combined varied significantly across DO (GAMM: $F=3.693 ; p=0.0166)$ and differ between habitats (GAMM: $F=11.48 ; p<0.0001$ ). On average, frequencies of occurrence were highest once DO reached $70 \%-80 \%$ saturation (Fig. 5a and b). The spread of the frequencies of occurrence around the median was also substantially reduced once DO was between $70 \%$ and $110 \%$ saturation, indicating that taxa were more equally frequent, 
Table 1. Summary of the environmental factors during the study period. For each factor, the minimum, maximum and mean ( \pm SE) values are provided for neap tides and spring tides on the edge and in-forest sites.

\begin{tabular}{|c|c|c|c|c|c|}
\hline \multirow{2}{*}{$\begin{array}{l}\text { Environmental } \\
\text { factors }\end{array}$} & \multirow[t]{2}{*}{ Values } & \multicolumn{2}{|c|}{ Neap } & \multicolumn{2}{|c|}{ Spring } \\
\hline & & Edge & In forest & Edge & In forest \\
\hline \multirow[t]{3}{*}{ DO (\% saturation) } & Min & 13.7 & 14.3 & 30.9 & 22.6 \\
\hline & $\operatorname{Max}$ & 110.6 & 114.4 & 105.5 & 103.3 \\
\hline & Mean $( \pm \mathrm{SE})$ & $67.2( \pm 0.6)$ & $71.4( \pm 0.6)$ & $75.8( \pm 0.7)$ & $79.5( \pm 0.7)$ \\
\hline \multirow{3}{*}{ Temperature $\left({ }^{\circ} \mathrm{C}\right)$} & Min & 26.2 & 25.8 & 25.9 & 25.1 \\
\hline & Max & 32.0 & 31.5 & 30.5 & 30.4 \\
\hline & Mean $( \pm$ SE) & $29.1( \pm 0.0)$ & $28.9( \pm 0.0)$ & $28.0( \pm 0.0)$ & $28.0( \pm 0.0)$ \\
\hline \multirow[t]{3}{*}{ Water depth $(\mathrm{cm})$} & Min & 1.1 & 0.0 & 2.4 & 0.0 \\
\hline & $\operatorname{Max}$ & 118.1 & 77.8 & 133.7 & 95.5 \\
\hline & Mean $( \pm S E)$ & $55( \pm 0.7)$ & $34( \pm 0.6)$ & $71( \pm 1.2)$ & $48( \pm 1.1)$ \\
\hline \multirow[t]{3}{*}{ Tidal range (m) } & Min & 0.35 & 0.35 & 1.25 & 1.25 \\
\hline & Max & 0.59 & 0.59 & 1.38 & 1.38 \\
\hline & Mean & 0.46 & 0.46 & 1.31 & 1.31 \\
\hline
\end{tabular}

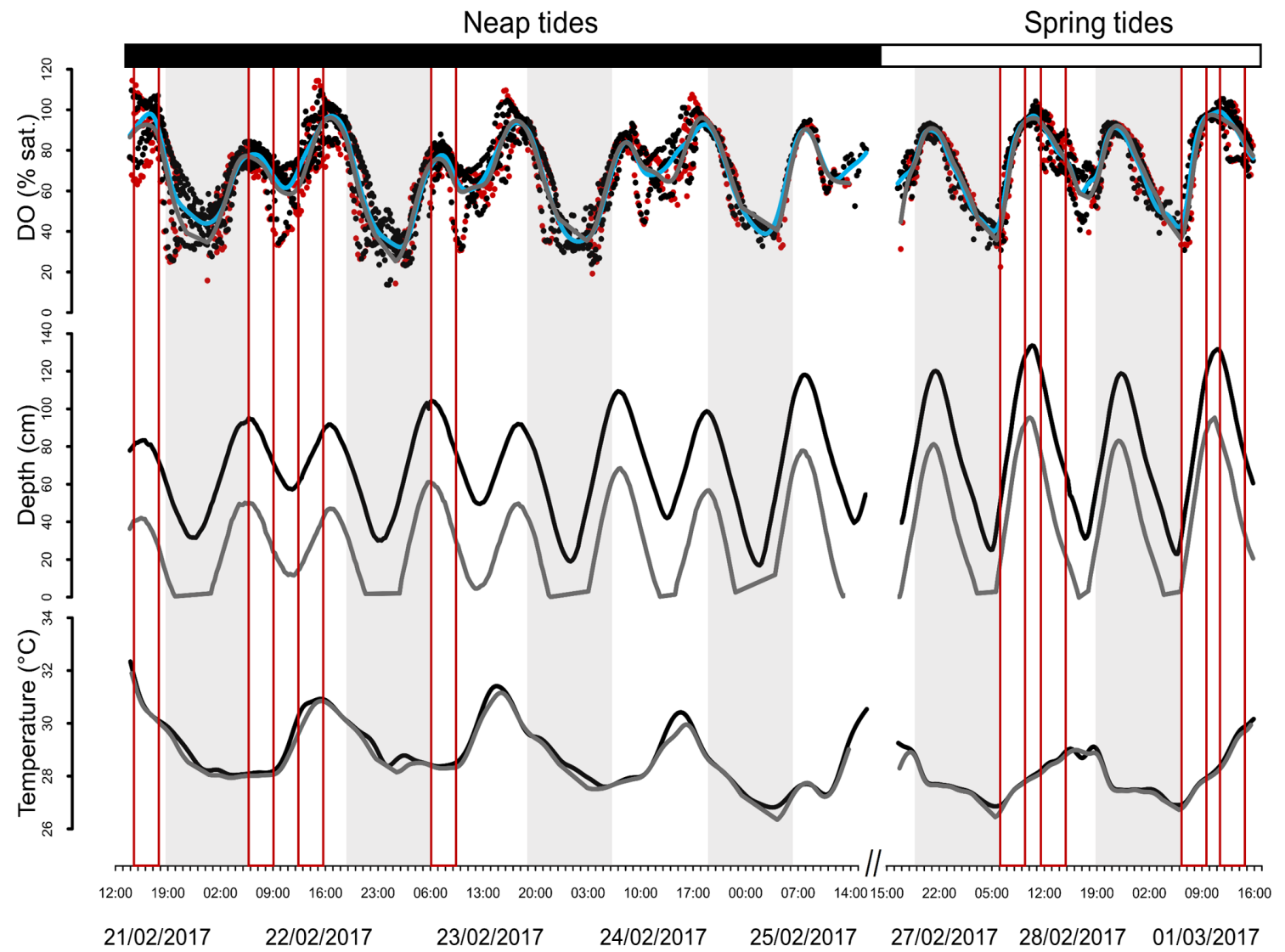

Figure 2. Cubic spline smoothers for dissolved oxygen (DO), depth and temperature. Data are from 21 to 25 February 2017 and from 27 February to 1 March 2017. For DO, edge sites are represented by the blue smoother and black points and in-forest sites by the grey smoother and red points. For the other factors, edge sites are represented by the black smoothers and in-forest sites by the grey smoothers. Shaded areas represent sunset to sunrise. Each red box represents an underwater camera sampling. 


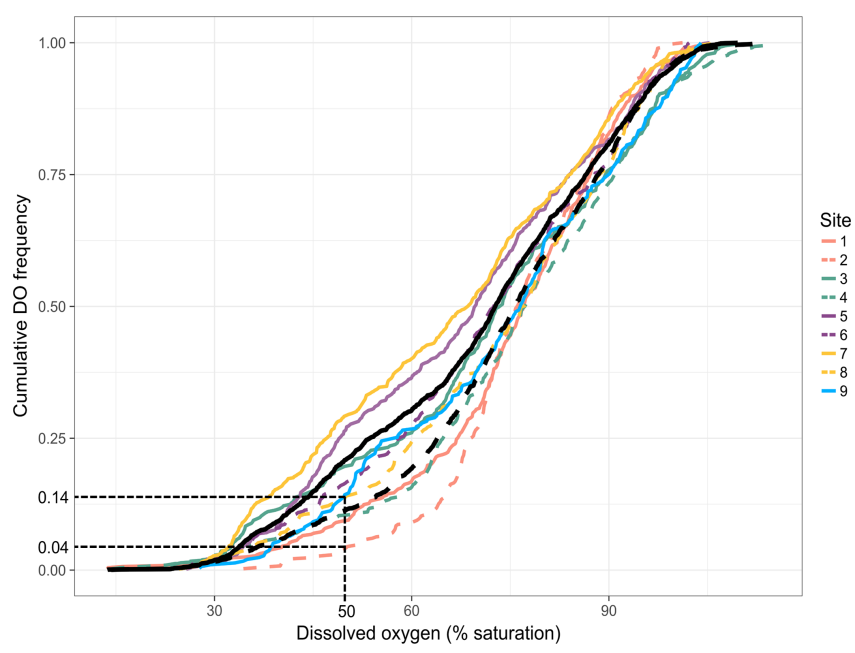

Figure 3. Site-specific cumulative DO frequencies. Each colour represents a paired site (edge and in forest), and edge sites are represented by solid coloured lines and in-forest sites by dashed coloured lines. The solid black line indicates the mean cumulative DO frequencies across edge sites and the dashed one the mean cumulative DO frequencies across in-forest sites. The frequency of hypoxia (DO $\leq 50 \%$ saturation) at sites 2 and 8 is indicated to help read the figure.

whereas at low DO levels only a few taxa were abundant, with the rest being rarely observed or absent entirely. The patterns of utilisation across DO intervals differed between the in-forest and edge habitat (Fig. 5a and b). Although, on average, the highest frequencies of occurrence were recorded once DO reached $70 \%-80 \%$ saturation for both habitats; there were larger disparities between taxa at edge sites, with some being frequently observed at low DO and some being rarely observed or absent entirely until DO reached $70 \%-$ $80 \%$ saturation (Fig. 5a), while at in-forest sites, frequencies of occurrence were more stable across DO (Fig. 5b).

Disparities in frequencies of occurrence between taxa were explained as fish appeared to respond differently to DO variations. We identified three distinct types of patterns of mangrove utilisation across DO while investigating speciesspecific variations in frequencies of occurrence across DO:

1. Pattern 1: "High tolerance". These taxa (19 taxa) were recorded across the entire range of DO (30\%-110\% saturation) and were usually known to use mangrove habitats extensively (Fig. 6; Table 2; Fig. A2a and b).

2. Pattern 2: "Medium tolerance". These taxa (seven taxa) were not observed once DO was below 50\%-60\% saturation and were also usually known to use mangrove habitats extensively (Fig. 6; Table 2; Fig. A2c).

3. Pattern 3: "Low tolerance". These taxa (10 taxa) were not observed once DO was below $70 \%-80 \%$ saturation and were usually reef-associated taxa (Fig. 6; Table 2; Fig. A2d).
Table 2. The 36 common fish taxa identified by underwater video cameras at Bouraké, New Caledonia. The superscript number corresponds to the type of patterns of mangrove utilisation across DO followed by the taxon (Fig. 6): Pattern 1 - "High tolerance", Pattern 2 - "Medium tolerance" - and Pattern 3 - "Low tolerance". Taxa highlighted in bold represent the 10 most common taxa. Taxa recorded in forest ( $5 \mathrm{~m}$ inside the forest) are underlined.

\begin{tabular}{|c|c|}
\hline Family & Taxon \\
\hline \multirow[t]{2}{*}{ Acanthuridae } & Acanthurus auranticavus 1 \\
\hline & Acanthurus grammoptilus ${ }^{3}$ \\
\hline Apogonidae & Fibramia lateralis 1 \\
\hline Carangidae & Caranx papuensis ${ }^{1}$ \\
\hline \multirow[t]{6}{*}{ Chaetodontidae } & Chaetodon auriga ${ }^{1}$ \\
\hline & $\overline{\text { Chaetodon bennetti }^{1}}$ \\
\hline & Chaetodon lineolatus $^{1}$ \\
\hline & Chaetodon lunula ${ }^{3}$ \\
\hline & Chaetodon vagabundus ${ }^{3}$ \\
\hline & Heniochus acuminatus $^{3}$ \\
\hline Clupeidae & Clupeidae spp. ${ }^{3}$ \\
\hline Gerreidae & $\overline{\text { Gerres oyena }} 2$ \\
\hline \multirow[t]{5}{*}{ Gobiidae } & $\overline{\text { Amoya gracilis }} 1$ \\
\hline & Asterropteryx sp. cf. striata ${ }^{1}$ \\
\hline & $\overline{\text { Cryptocentrus leptocephalus }}^{3}$ \\
\hline & Gobiidae spp. ${ }^{1}$ \\
\hline & $\overline{\text { Redigobius balteatus } 1}$ \\
\hline \multirow[t]{2}{*}{ Haemulidae } & $\overline{\text { Plectorhinchus spp. }^{2}}$ \\
\hline & $\overline{\text { Pomadasys argenteus }}^{2}$ \\
\hline \multirow[t]{2}{*}{ Lethrinidae } & Lethrinus harak ${ }^{2}$ \\
\hline & Lethrinus lentjan ${ }^{3}$ \\
\hline \multirow[t]{4}{*}{ Lutjanidae } & Lutjanus argentimaculatus 1 \\
\hline & Lutjanus fulviflamma $^{1}$ \\
\hline & Lutjanus fulvus $^{1}$ \\
\hline & $\overline{\text { Lutjanus russellii }}^{1}$ \\
\hline \multirow{2}{*}{$\begin{array}{l}\text { Monodactylidae } \\
\text { Mugilidae }\end{array}$} & Monodactylus argenteus 1 \\
\hline & Mugilidae spp. ${ }^{1}$ \\
\hline \multirow[t]{3}{*}{ Mullidae } & 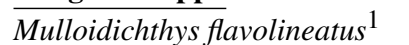 \\
\hline & Parupeneus indicus 3 \\
\hline & Upeneus tragula $^{2}$ \\
\hline Pomacanthidae & Pomacanthus sexstriatus 3 \\
\hline Pomacentridae & Neopomacentrus spp. ${ }^{1}$ \\
\hline Scaridae & $\overline{\text { Scarus sp. cf. ghobban }} n^{3}$ \\
\hline Siganidae & $\begin{array}{l}\text { Siganus canaliculatus } \\
\text { Siganus lineatus }\end{array}$ \\
\hline Sparidae & 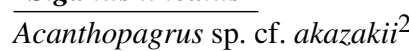 \\
\hline
\end{tabular}

Figure 6 only shows one example of taxa per type of patterns; however, all the species-specific patterns are provided in Fig. A2a, b, c and d.

The type of patterns followed by a taxon appeared to significantly influence its overall frequency of occurrence (Fig. 7; Kruskal-Wallis: $\chi^{2}=9.8757 ; p<0.01$ ). Taxa following a "High tolerance" pattern were on average signifi- 
(a)

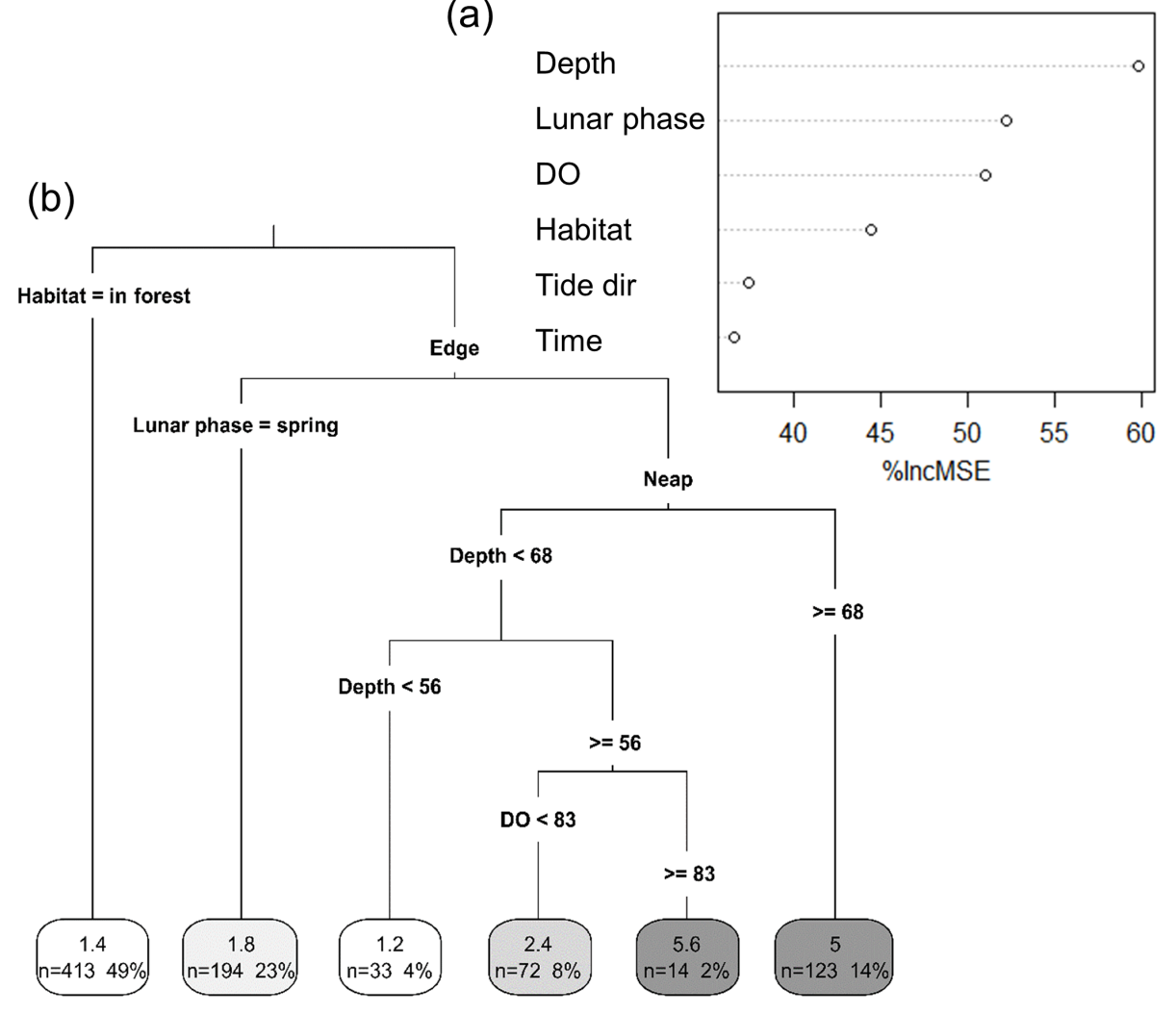

Figure 4. Importance of different environmental factors in explaining variations in taxonomic richness. (a) Random forest importance plot. Importance plot was obtained from a random forest model built with Depth (cm), Lunar phase (neap vs spring), DO (dissolved oxygen; $\%$ saturation), Time (time of day; morning vs afternoon), Tide dir (tide direction; flooding vs. ebbing) and Habitat (in forest vs. edge) as predictors for taxonomic richness. (b) Univariate classification tree. The tree was built using the same variables and provides a visual interpretation of the random forest model. Numbers in the boxes in each terminal leaf represent the average taxonomic richness, the number of 5 min intervals $(n)$ and the total percentage of 5 min intervals that $n$ represents.

cantly more frequently observed than taxa following a "Low tolerance" pattern (Dunn test: $p<0.01$ ). Overall frequencies of occurrence of taxa following a "Medium tolerance" pattern were intermediate but not significantly different than "High tolerance" taxa (Dunn test: $p>0.5$ ) or "Low tolerance" taxa (Dunn test: $p>0.1$ ).

\section{Discussion}

\subsection{Depth and DO are both potential factors for observed tidal migrations}

Fish assemblages were shown to be highly variable over time and space in the study area (Dubuc et al., 2019). About half of this variability was explained by multiple environmental factors, among which depth, DO, lunar phase and location within the mangrove forest (edge or in forest) were the most important. The main trend identified among the temporal variability in fish assemblages occurred at a tidal scale (Dubuc et al., 2019), highlighting that fish were responding to one or several factors covarying with tide. The effects of lunar phase and location on fish assemblages were investigated in detail in Dubuc et al. (2019); therefore the following discussion focuses on water depth and DO, which both varied at a tidal scale. Tidal variations in fish assemblages are common in intertidal environments (Laroche et al., 1997; Ellis and Bell, 2008; Becker et al., 2012); however, the factors responsible for their occurrence have rarely been investigated. There was a high collinearity between depth and DO, as both varied across the tidal cycle, and these two factors were greatly important in explaining variations in fish assemblages. Consequently, it is likely that depth and DO play an essential role in triggering tidal migrations. Previous studies have shown that fish can respond to both water depth and DO changes (Wannamaker and Rice, 2000; Bretsch and Allen, 2006; Johnston and Sheaves, 2007; Rountree and Able, 2007; Ellis and Bell, 2008; Brady and Targett, 2013), emphasising the idea that fish could be using depth and DO interchangeably as cues to initiate tidal migrations, a trigger that might be dependent on the perceived upcoming risk (stranding or hypoxia). 

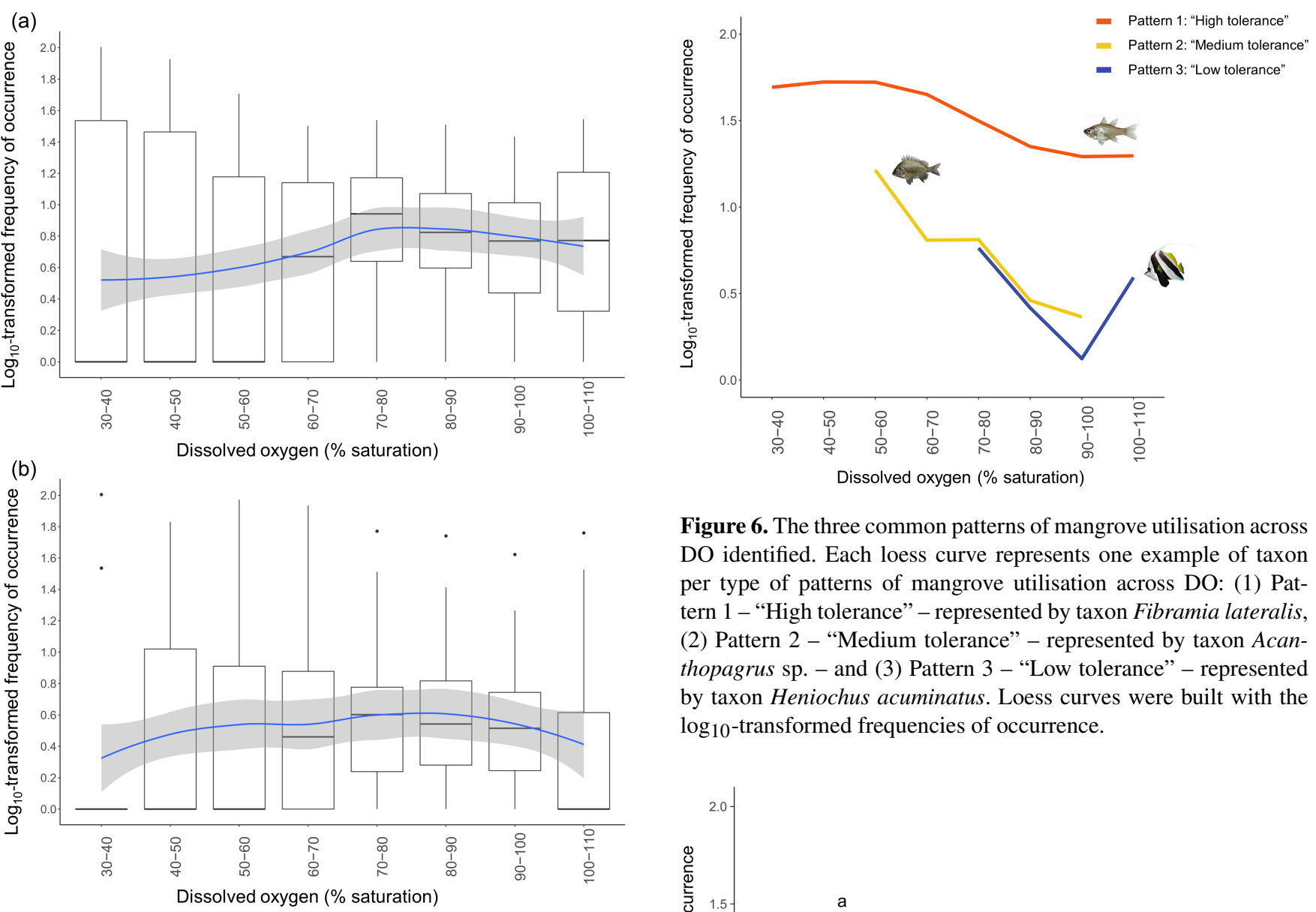

Figure 6. The three common patterns of mangrove utilisation across DO identified. Each loess curve represents one example of taxon per type of patterns of mangrove utilisation across DO: (1) Pattern 1 - "High tolerance" - represented by taxon Fibramia lateralis, (2) Pattern 2 - "Medium tolerance" - represented by taxon Acanthopagrus sp. - and (3) Pattern 3 - "Low tolerance" - represented by taxon Heniochus acuminatus. Loess curves were built with the $\log _{10}$-transformed frequencies of occurrence.

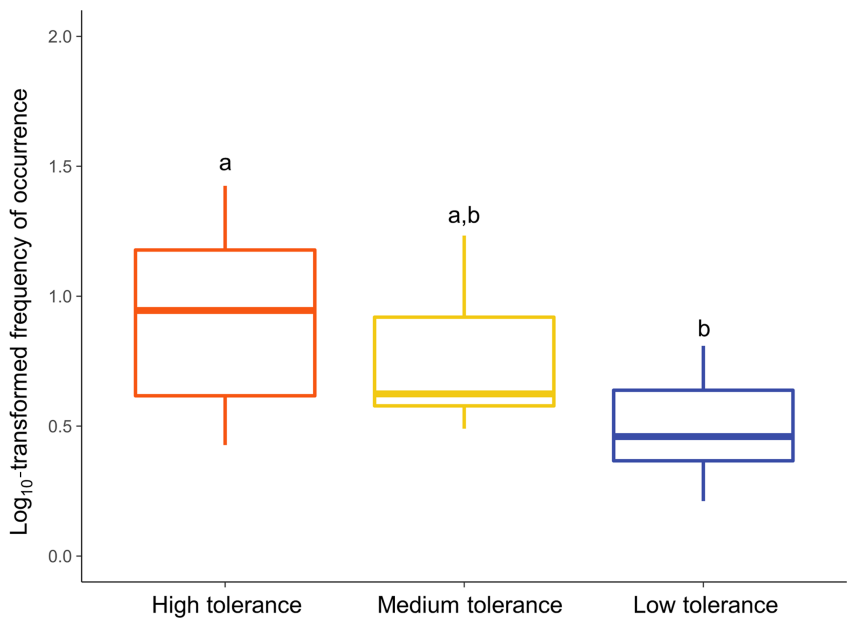

Depth becomes limiting when fish cannot safely access the area because it is too shallow, with associated risk of stranding. However, many taxa, including small-sized species, avoided mangrove habitats even when they potentially had enough water (Dubuc et al., 2019). On the other hand, changes in DO can rapidly impair fish fitness (Chabot and Claireaux, 2008; Vaquer-Sunyer and Duarte, 2008). Indeed, in aquatic environments, DO is considered to be the primary limiting factor (Fry, 1971; Claireaux and Chabot, 2016), as it is naturally scarcer than in the atmosphere (Diaz, 2001), making it a perpetual challenge for fish to access available oxygen in the water. In the mangrove forest examined here, changes in DO across tide were extreme, with up to $80 \%$ loss during half of a tidal period (high to low), supporting the notion that DO could be an important constraint for fish to access mangrove habitats even when depth is suitable. Consid-

Figure 7. Relationship between frequencies of occurrence and type of patterns followed. Overall frequencies of occurrence were calculated for each common taxon at the DO range corresponding to that taxon's assigned pattern of utilisation. Differential letters above boxes denote statistically different means of frequency of occurrence among types of patterns of utilisation (Dunn test: $p<0.05$ ).

ering the relevance of both factors, and the fact that the risk of stranding and hypoxia are concomitant, it is likely that fish are adapted to respond to either depth or DO, depending on which one becomes limiting first, and this may vary among taxa.

The hypothesis that fish can interchangeably respond and tolerate adverse depth and DO conditions was supported by 
the fact that all taxa that access mangrove habitats at low depth in Bouraké (Pattern 3 - "Low-depth users"; Dubuc et al., 2019) were all following a "High tolerance" pattern here in response to DO, indicating that they were able to tolerate low depth as well as low DO. The effects of depth and DO might well be mostly confounded, as DO fluctuations overall follow depth; however, DO amplitude (difference between minimum and maximum levels) depends on many interacting factors, including weather (Tyler et al., 2009), local geomorphology, or biological and chemical activities (Mazda et al., 1990; Peña et al., 2010). Therefore, minimum and maximum DO levels for a same depth can differ and vary in complex spatial and temporal scales, independent of the tidal scale, probably explaining why depth and DO were both highlighted as important factors. These results emphasise the importance of understanding the DO dynamics and its impacts on fish to comprehend how mangrove forests are being used. Future targeted sampling could for instance specifically investigate fish movements at the end of ebbing tides experiencing relatively high DO and low DO, as on the 28 February afternoon and morning respectively. This would help to determine whether fish consistently leave mangrove habitats at a same depth or whether responses are indeed affected by DO levels being abnormally low or high.

\subsection{Tidally induced dissolved oxygen variations}

During this study, we hypothesised that DO could be an important limiting factor for fish utilising intertidal mangrove forests, and our findings support this hypothesis. However, the associated risk of hypoxia in the study system was still to be tested. Diel hypoxia conditions observed in other mangrove systems (Knight et al., 2013; Dubuc et al., 2017; Gedan et al., 2017; Mattone and Sheaves, 2017) were also a seemingly common condition in Bouraké. DO showed extreme and rapid fluctuations with the diel and tidal cycles. Low DO was recorded daily and was most severe during nighttime ebbing tide, reaching levels that can compromise fish fitness (Rogers et al., 2016). It is likely that hypoxia is a common condition of intertidal mangrove forests due to the mineralisation of a large amount of organic matter produced by mangrove trees, responsible for a high consumption of oxygen by bacteria (Alongi et al., 2004; Dittmar et al., 2006), but also due to the exchange of porewater between sediments and the water column, known as "tidal pumping" (Li et al., 2009; Gleeson et al., 2013; Call et al., 2015; Leopold et al., 2017). Briefly, at each flooding tide, water infiltrates intertidal sediments and then drains back to the water column during the next ebbing tide, while in the sediments, water becomes enriched in reduced compounds such as $\mathrm{NH}_{3}, \mathrm{H}_{2} \mathrm{~S}$ and $\mathrm{FeS}_{2}$, resulting in water acidification and deoxygenation (Marchand et al., 2011). As porewater accumulates in the water column throughout the ebbing tide (Bouillon et al., 2007), it drives extreme drops of oxygen usually observed at low tide. Connectivity with the Pritzbuer Bay was crucial here in this mangrove-coral semi-enclosed lagoon, as the flooding tide presumably brings oceanic water that is more saturated, replenishing DO levels. During spring tides, higher DO levels were recorded, probably driven by higher water renewal compared to neap tides. There was no difference observed between DO dynamics on the edge and in forest; however minimum values were slightly lower on the edge because water remained permanently at low tide, being subjected to further decline compared to the in-forest site that became exposed earlier during the tide and therefore experienced a shorter DO decline period.

\subsection{Responses to DO variations}

Fish significantly responded to daytime DO variations, with taxonomic richness and average frequencies of occurrence being higher and more consistent once DO reached $70 \%-$ $80 \%$ saturation. Even though fish data were only collected during daytime when photosynthesis occurs, this result indicated that DO levels reached during the study were probably low enough to cause harmful effects, and, therefore, many taxa responded by temporarily avoiding the area. Apparent behavioural avoidance thresholds observed were somewhat species-specific, being initiated at different DO levels potentially driven by differential tolerances to low DO (Claireaux and Chabot, 2016). However, three broad groups of patterns of mangrove utilisation were identified, driven by taxa's behavioural avoidance thresholds. Most taxa did not display any behavioural avoidance (i.e. most taxa exhibited a "High tolerance" pattern), and some of these taxa even reached their maximum frequency of occurrence at the lowest DO levels recorded (30\%-40\% saturation). Most of these taxa, such as L. argentimaculatus, Mugilidae spp. and Gobiidae spp. (Froese and Pauly, 2017), are known to extensively use mangrove habitats (Sheaves et al., 2016; Dubuc et al., 2019). On the other hand, other taxa were not observed either below 50\%-60\% saturation ("Medium tolerance" pattern) or below $70 \%-80 \%$ saturation ("Low tolerance" pattern). Taxa following a "Low tolerance" pattern were mostly reef-associated species and therefore are not usually seen in mangrove habitats, such as C. vagabundus, H. acuminatus and Scarus sp. (Froese and Pauly, 2017). The three different types of patterns of utilisation observed may highlight that taxa following a "High tolerance" pattern, and therefore taxa commonly seen in mangrove habitats, are more tolerant to low DO than taxa following "Medium tolerance" and "Low tolerance" patterns.

Even though the underlying adaptations behind these patterns still need to be investigated, these observations suggest that DO tolerance may partly explain species reliance on mangrove habitats. Indeed, taxa extensively using mangrove habitats, such as L. argentimaculatus, Mugilidae spp. and Gobiidae spp., displayed an apparent higher tolerance to hypoxia than taxa occasionally using mangrove habitats, such as L. harak and Plectorhinchus spp., displaying a higher 
tolerance themselves than species not usually found in mangroves but in coral reefs such as $C$. vagabundus, H. acuminatus and Scarus sp. (Sheaves et al., 2016; Froese and Pauly, 2017; Dubuc et al., 2019). Tolerance to low DO provides an evident benefit, as taxa can use mangrove habitats more often and for longer periods compared to taxa that need to migrate temporarily to avoid harmful DO levels. Moreover, remaining in low DO when most other taxa must leave can provide opportunistic feeding and limited competition (Diaz et al., 1992; Rahel and Nutzman, 1994). On the other hand, tidal migrations can have indirect costs, as they can increase risk exposure to predators as fish travel to open water, aggregate fish in suboptimal habitats (less food and more predation) while waiting for DO conditions to improve and increase energetic costs during extended swimming activities (Eby et al., 2005; Shoji et al., 2005; Chabot and Claireaux, 2008; Craig, 2012). This implies that being adapted to withstand low DO might be an important feature of taxa using mangrove habitats extensively and spending a large part of their time in these habitats.

No differences in DO levels were found between the edge and inside of the forest, suggesting that observed differences in fish assemblages between the two habitats could be explained by depth, especially the fact that in-forest sites get exposed during low tide while edge sites remain submerged. However, it was interesting to note that most taxa venturing in forest (23 taxa) were following a "High tolerance" pattern (16 taxa; 4 taxa were following a "Medium tolerance" pattern and 3 taxa a "Low tolerance" pattern). In other mangrove forests, DO can reach levels close to $0 \%$ saturation (Knight et al., 2013; Mattone and Sheaves, 2017), so it is possible that such lethal levels are also occasionally reached in Bouraké. In addition to the risk of stranding, the risk of developing hypoxia could explain why relatively few taxa venture inside the forest (Sheaves et al., 2016; Dubuc et al., 2019), and those that do appear to be highly tolerant to hypoxia.

\section{Conclusions}

The overall value of mangrove forests has been linked to parameters such as geographical location, tidal range (micro-, meso- or macrotidal), setting (coastal, estuarine, island or embayment) and connectivity to adjacent habitats (Unsworth et al., 2008; Igulu et al., 2014; Bradley et al., 2019). While these factors provide important information, this study also shows that for a same mangrove forest, its value is temporally and spatially variable. About half of the variability in fish assemblages was explained by changes in depth, DO, lunar phase, position within the mangrove forest, time of day and tide direction. Most of the temporal variability occurred on a tidal scale, highlighting the importance of tide in driving mangrove forests' utilisation. Here, depth and DO were mostly considered to explain tidal variations in fish assemblages; however, tide can induce variations in many other factors. For instance, a recent study suggested that the resuspension of mangrove-derived organic matter via porewater exchange could temporally boost primary and secondary production, attracting fish regardless of water quality conditions (David et al., 2018). These results highlight the complexity of quantifying the utilisation and, consequently, the value of mangrove forests and call for more investigations especially on the effects of tide.

This study is the first to provide insights on how mangrove forests' utilisation by fish is influenced by DO. It suggests that tolerance to low DO may be a widespread adaptation for taxa commonly using mangrove forests and could explain why they manage to thrive in these harsh environments. The need of being tolerant to low DO, or being able to undertake tidal migrations while limiting alternative costs, is likely to limit the number of taxa using intertidal mangrove habitats that experience low DO. However, with only field data, it is difficult to attribute specific fish responses to DO. Physiological techniques could be used to determine whether a difference in hypoxia tolerance could explain why some species access mangrove habitats at low DO levels while others access them at higher DO levels (Lawton, 1991; McGill et al., 2006). This is the first study to look at, and suggest, a relationship between DO and fish utilisation of mangrove habitats. It adds to our knowledge on factors determining mangrove habitat value and highlights the importance of considering DO to be a key controlling factor. More in-depth evaluation of DO dynamics and its impacts on fish populations in other locations would certainly help in understanding the heterogeneous value of intertidal mangrove forests.

Data availability. All relevant data are freely available online on the Tropical Data Hub repository: https://doi.org/10.25903/5cd4d312cbcfb (Dubuc, 2019). 
Appendix A

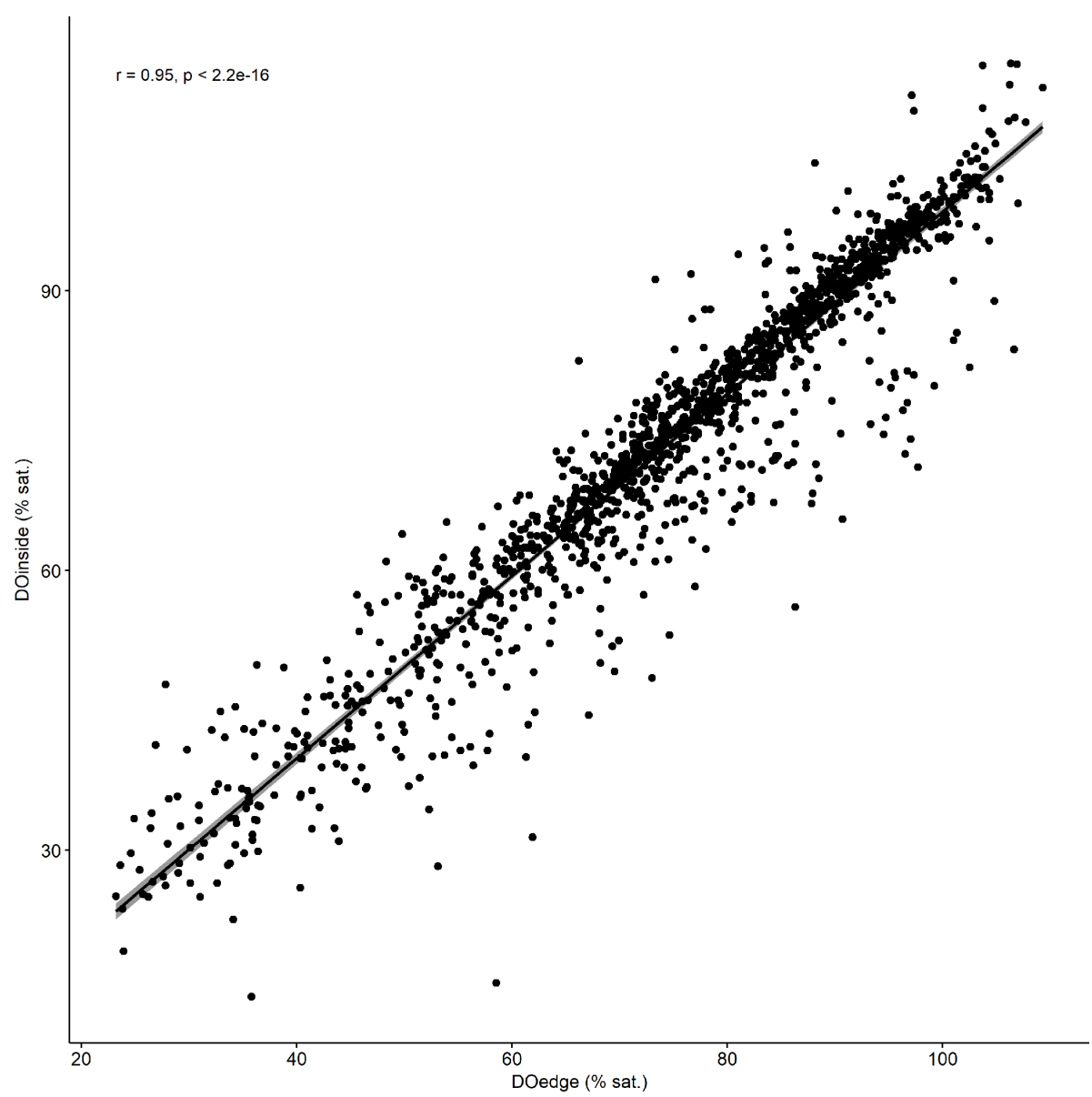

Figure A1. Kendall's correlation test used to determine whether patterns of change in DO were significantly correlated between edge and in-forest sites. DOedge: DO recorded in edge sites; DOinside: DO recorded in in-forest sites. 
Table A1. The full list of taxa identified by underwater video cameras at Bouraké, New Caledonia.

\begin{tabular}{|c|c|}
\hline Family & Taxon \\
\hline Acanthuridae & $\begin{array}{l}\text { Acanthurus auranticavus } \\
\text { Acanthurus grammoptilus } \\
\text { Acanthurus sp. cf. blochii } \\
\text { Ctenochaetus } \mathrm{sp} . \\
\text { Zebrasoma velifer }\end{array}$ \\
\hline Apogonidae & $\begin{array}{l}\text { Fibramia lateralis } \\
\text { Ostorhinchus septemstriatus }\end{array}$ \\
\hline Belonidae & Belonidae spp. \\
\hline Blenniidae & Blenniidae spp. \\
\hline Carangidae & $\begin{array}{l}\text { Caranx ignobilis } \\
\text { Caranx papuensis } \\
\text { Caranx } \mathrm{sp} .\end{array}$ \\
\hline Chaetodontidae & $\begin{array}{l}\text { Chaetodon auriga } \\
\text { Chaetodon bennetti } \\
\text { Chaetodon ephippium } \\
\text { Chaetodon flavirostris } \\
\text { Chaetodon lineolatus } \\
\text { Chaetodon lunula } \\
\text { Chaetodon melannotus } \\
\text { Chaetodon speculum } \\
\text { Chaetodon vagabundus } \\
\text { Heniochus acuminatus }\end{array}$ \\
\hline Clupeidae & Clupeidae spp. \\
\hline Diodontidae & Diodon hystrix \\
\hline Ephippidae & Platax pinnatus \\
\hline Fistulariidae & Fistularia spp. \\
\hline Gerreidae & $\begin{array}{l}\text { Gerres filamentosus } \\
\text { Gerres oyena }\end{array}$ \\
\hline Gobiidae & $\begin{array}{l}\text { Amblygobius linki } \\
\text { Amblygobius nocturnus } \\
\text { Amoya gracilis } \\
\text { Asterropteryx sp. cf. striata } \\
\text { Cryptocentrus leptocephalus } \\
\text { Eviota sp. } \\
\text { Exyrias puntang } \\
\text { Gobiidae spp. } \\
\text { Gobiidae spp. } 2 \\
\text { Redigobius balteatus }\end{array}$ \\
\hline Haemulidae & $\begin{array}{l}\text { Plectorhinchus lineatus } \\
\text { Plectorhinchus spp. } \\
\text { Pomadasys argenteus }\end{array}$ \\
\hline Hemiramphidae & Hyporhamphus sp. \\
\hline Labridae & $\begin{array}{l}\text { Choerodon graphicus } \\
\text { Labridae spp. }\end{array}$ \\
\hline Lethrinidae & $\begin{array}{l}\text { Lethrinus harak } \\
\text { Lethrinus lentjan } \\
\text { Lethrinus obsoletus }\end{array}$ \\
\hline Lutjanidae & $\begin{array}{l}\text { Lutjanus argentimaculatus } \\
\text { Lutjanus fulviflamma } \\
\text { Lutjanus fulvus } \\
\text { Lutjanus russellii }\end{array}$ \\
\hline
\end{tabular}

Table A1. Continued.

\begin{tabular}{ll}
\hline Family & Taxon \\
\hline Monodactylidae & Monodactylus argenteus \\
Mugilidae & Mugilidae spp. \\
Mullidae & $\begin{array}{l}\text { Mulloidichthys flavolineatus } \\
\text { Parupeneus ciliatus }\end{array}$ \\
& Parupeneus indicus \\
& Upeneus tragula \\
Pomacanthidae & Pomacanthus sexstriatus \\
Pomacentridae & Neopomacentrus spp. \\
Scaridae & Bolbometopon muricatum \\
& Scarus sp. cf. ghobban \\
Scatophagidae & Scatophagus argus \\
Serranidae & Epinephelus caeruleopunctatus \\
& Epinephelus lanceolatus \\
& Epinephelus malabaricus \\
Epinephelus sp. \\
Siganidae & $\begin{array}{l}\text { Siganus } \text { canaliculatus } \\
\text { Siganus lineatus }\end{array}$ \\
Sparidae & Siganus punctatus \\
Sphyraenidae & Acanthopagrus sp. cf. akazakii \\
Tetraodontidae & Sphyraena barracuda \\
& Arothron hispidus \\
\hline &
\end{tabular}



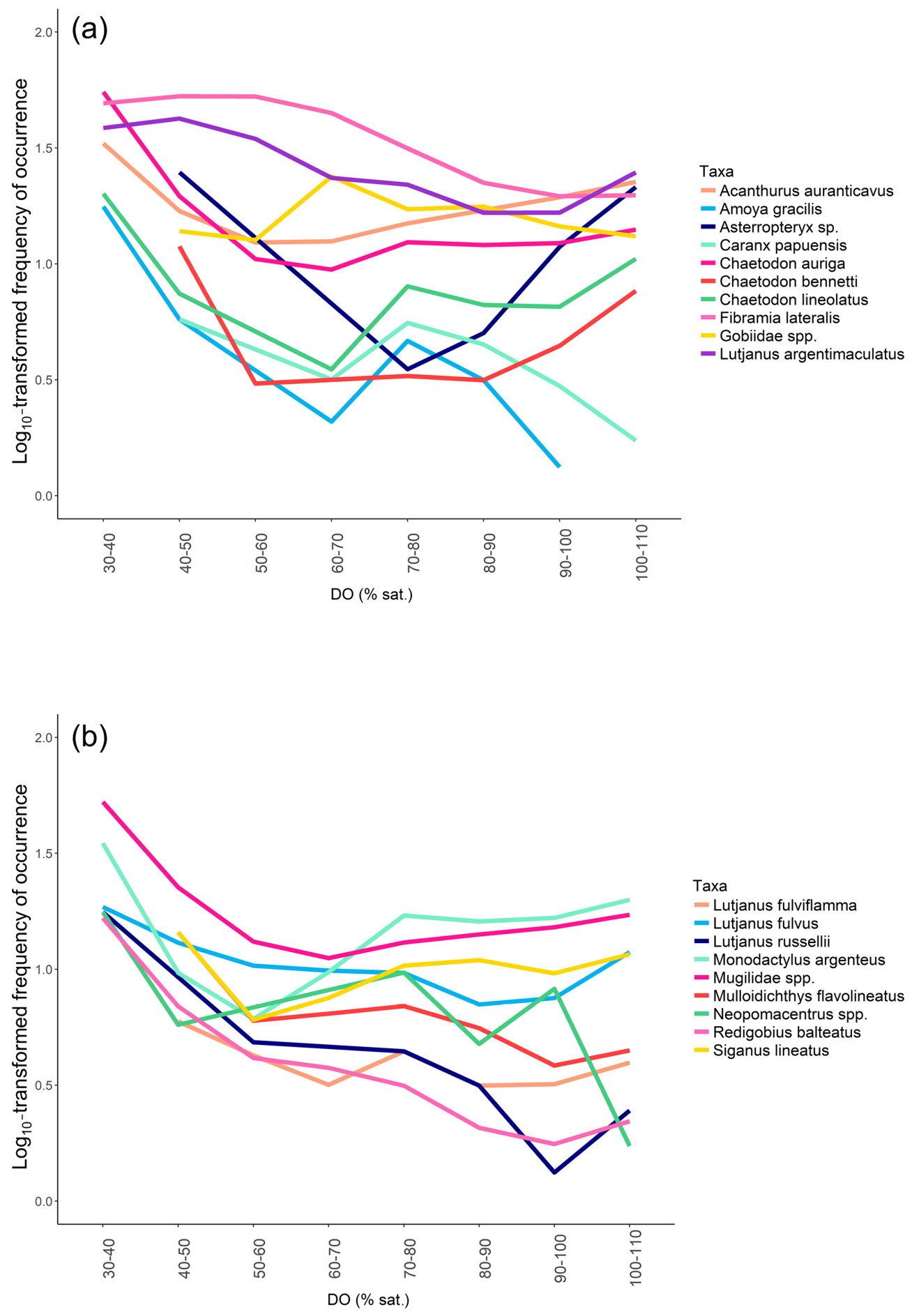

Taxa

- Lutjanus fulviflamma

- Lutjanus fulvus

- Lutjanus russellii

- Monodactylus argenteus

- Mugilidae spp.

- Mulloidichthys flavolineatus

- Neopomacentrus spp.

- Redigobius balteatus

- Siganus lineatus

Figure A2. 

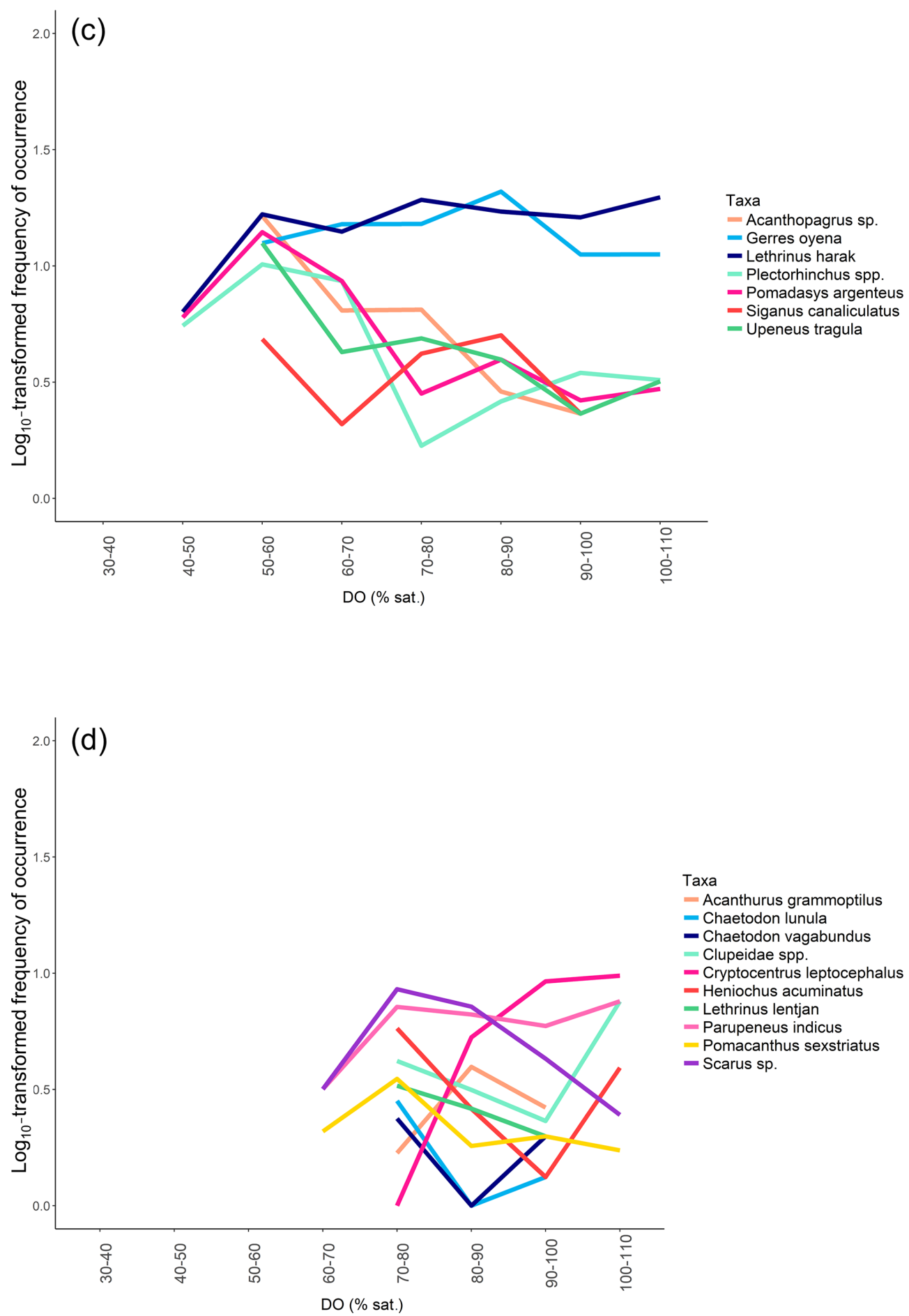

Taxa

- Acanthurus grammoptilus

- Chaetodon lunula

- Chaetodon vagabundus

- Clupeidae spp.

- Cryptocentrus leptocephalus

- Heniochus acuminatus

- Lethrinus lentjan

- Parupeneus indicus

- Pomacanthus sexstriatus

- Scarus sp.

Figure A2. Species-specific patterns of mangrove utilisation grouped by type of patterns: (a) Pattern 1 - "High tolerance, (b) Pattern 1 - "High tolerance" (continued), (c) Pattern 2 - "Medium tolerance" - and (d) Pattern 3 - "Low tolerance". 
Supplement. The supplement related to this article is available online at: https://doi.org/10.5194/bg-16-3959-2019-supplement.

Author contributions. AD, CM, NJW and MS contributed to the conceptualisation. AD led the investigation, project administration, formal analysis, visualisation and writing. CM, NJW, RB and MS assisted with supervision and writing.

Competing interests. The authors declare that they have no conflict of interest.

Special issue statement. This article is part of the special issue "Ocean deoxygenation: drivers and consequences - past, present and future (BG/CP/OS inter-journal SI)". It is a result of the International Conference on Ocean Deoxygenation, Kiel, Germany, 3-7 September 2018.

Acknowledgements. We are grateful to Adrien Jacotot, Thanh Nho Nguyen and Clara Hass for their assistance in the field and to the members of the Science for Integrated Coastal Ecosystem Management group for providing suggestions that improved the paper.

Financial support. This research has been supported by the Australian Department of Foreign Affairs and Trade (DFAT; grant no. ST000K7U8).

Review statement. This paper was edited by Kenneth Rose and reviewed by Keryn Gedan and one anonymous referee.

\section{References}

Alongi, D. M., Sasekumar, A., Chong, V. C., Pfitzner, J., Trott, L. A., Tirendi, F., Dixon, P., and Brunskill, G. J.: Sediment accumulation and organic material flux in a managed mangrove ecosystem: estimates of land-ocean-atmosphere exchange in peninsular Malaysia, Mar. Geol., 208, 383-402, 2004.

Baker, R., Sheaves, M., and Johnston, R.: Geographic variation in mangrove flooding and accessibility for fishes and nektonic crustaceans, Hydrobiologia, 762, 1-14, 2015.

Becker, A., Coppinger, C., and Whitfield, A. K.: Influence of tides on assemblages and behaviour of fishes associated with shallow seagrass edges and bare sand, Mar. Ecol. Prog. Ser., 456, 187199, 2012.

Bouillon, S., Middelburg, J. J., Dehairs, F., Borges, A. V., Abril, G., Flindt, M. R., Ulomi, S., and Kristensen, E.: Importance of intertidal sediment processes and porewater exchange on the water column biogeochemistry in a pristine mangrove creek (Ras Dege, Tanzania), Biogeosciences, 4, 311-322, https://doi.org/10.5194/bg-4-311-2007, 2007.
Bradley, M., Baker, R., Nagelkerken, I., and Sheaves, M.: Context is more important than habitat type in determining use by juvenile fish, Landsc. Ecol. Eng., 34, 427-442, 2019.

Brady, D. C. and Targett, T. E.: Movement of juvenile weakfish Cynoscion regalis and spot Leiostomus xanthurus in relation to diel-cycling hypoxia in an estuarine tidal tributary, Mar. Ecol. Prog. Ser., 491, 199-219, 2013.

Breiman, L.: Random Forests, in: Machine Learning, edited by: Schapire, R. E., Kluwer Academic Publishers, the Netherlands, 5-32, 2001.

Breitburg, D.: Effects of hypoxia, and the balance between hypoxia and enrichment, on coastal fishes and fisheries, Estuaries, 25, 767-781, 2002.

Breitburg, D., Levin, L. A., Oschlies, A., Grégoire, M., Chavez, F. P., Conley, D. J., Garçon, V., Gilbert, D., Gutiérrez, D., Isensee, K., Jacinto, G. S., Limburg, K. E., Montes, I., Naqvi, S. W. A., Pitcher, G. C., Rabalais, N. N., Roman, M. R., Rose, K. A., Seibel, B. A., Telszewski, M., Yasuhara, M., and Zhang, J.: Declining oxygen in the global ocean and coastal waters, Science, 359, eaam7240, https://doi.org/10.1126/science.aam7240, 2018.

Breitburg, D. L.: Behavioral response of fish larvae to low dissolved-oxygen concentrations in a stratified water column, Mar. Biol., 120, 615-625, 1994.

Bretsch, K. and Allen, D. M.: Tidal migrations of nekton in salt marsh intertidal creeks, Estuar. Coast., 29, 474-486, 2006.

Buffoni, G. and Cappelletti, A.: Oxygen dynamics in a highly trophic aquatic environment. The case of Orbetello coastal lagoon, Estuar. Coast. Shelf Sci., 49, 763-774, 1999.

Call, M., Maher, D. T., Santos, I. R., Ruiz-Halpern, S., Mangion, P., Sanders, C. J., Erler, D. V., Oakes, J. M., Rosentreter, J., Murray, R., and Eyre, B. D.: Spatial and temporal variability of carbon dioxide and methane fluxes over semi-diurnal and spring-neapspring timescales in a mangrove creek, Geochim. Cosmochim. Ac., 150, 211-225, 2015.

Chabot, D. and Claireaux, G.: Environmental hypoxia as a metabolic constraint on fish: The case of Atlantic cod, Gadus morhua, Mar. Pollut. Bull., 57, 287-294, 2008.

Claireaux, G. and Chabot, D.: Responses by fishes to environmental hypoxia: integration through Fry's concept of aerobic metabolic scope, J. Fish Biol., 88, 232-251, 2016.

Craig, J. K.: Aggregation on the edge: effects of hypoxia avoidance on the spatial distribution of brown shrimp and demersal fishes in the Northern Gulf of Mexico, Mar. Ecol. Prog. Ser., 445, 75-95, 2012.

D'Avanzo, C. and Kremer, J. N.: Diel oxygen dynamics and anoxic events in an eutrophic estuary of Waquoit Bay, Massachusetts, Estuaries, 17, 131-139, 1994.

David, F., Marchand, C., Taillardat, P., Thành-Nho, N., and Meziane, T.: Nutritional composition of suspended particulate matter in a tropical mangrove creek during a tidal cycle (Can Gio, Vietnam), Estuar. Coast. Shelf Sci., 200, 126-130, 2018.

Davis, T. L. O.: Temporal changes in the fish fauna entering a tidal swamp system in tropical Australia, Environ. Biol. Fish., 21, 161-172, 1988.

Diaz, R. J.: Overview of hypoxia around the world, J. Environ. Qual., 30, 275-281, 2001.

Diaz, R. J. and Rosenberg, R.: Marine benthic hypoxia: A review of its ecological effects and the behavioural responses of benthic macrofauna, in: Oceanography and Marine Biology - An Annual 
Review, edited by: Ansell, A. D., Gibson, R. N., and Barnes, M., UCL Press, London, 245-303, 1995.

Diaz, R. J. and Rosenberg, R.: Spreading dead zones and consequences for marine ecosystems, Science, 321, 926-929, 2008.

Diaz, R. J., Neubauer, R. J., Schaffner, L. C., Pihl, L., and Baden, S. P.: Continuous monitoring of dissolved oxygen in an estuary experiencing periodic hypoxia and the effect of hypoxia on macrobenthos and fish, in: Marine Coastal Eutrophication, edited by: Vollenweider, R. A., Marchetti, R., and Viviani, R., Elsevier, Amsterdam, 1055-1068, 1992.

Dittmar, T., Hertkorn, N., Kattner, G., and Lara, R. J.: Mangroves, a major source of dissolved organic carbon to the oceans, Global Biogeochem. Cy., 20, GB1012, https://doi.org/10.1029/2005GB002570, 2006.

Driedzic, W. R., Hochachka, P. W.: Metabolism in Fish During Exercise, in: Fish Physiology, edited by: Hoar, W. S. and Randall, D. J., Academic Press, Inc., New York, 503-543, 1978.

Dubuc, A.: Dataset: Fish assemblages and environmental parameters in Bourake, James Cook University, https://doi.org/10.25903/5cd4d312cbcfb, 2019.

Dubuc, A., Waltham, N., Malerba, M., and Sheaves, M.: Extreme dissolved oxygen variability in urbanised tropical wetlands: The need for detailed monitoring to protect nursery ground values, Estuar. Coast. Shelf Sci., 198, 163-171, 2017.

Dubuc, A., Waltham, N. J., Baker, R., Marchand, C., and Sheaves, M.: Patterns of fish utilisation in a tropical Indo-Pacific mangrove-coral seascape, New Caledonia, PLoS ONE, 14, e0207168, https://doi.org/10.1371/journal.pone.0207168, 2019.

Eby, L. A., Crowder, L. B., McClellan, C. M., Peterson, C. H., and Powers, M. J.: Habitat degradation from intermittent hypoxia: impacts on demersal fishes, Mar. Ecol. Prog. Ser., 291, 249-261, 2005.

Ellis, W. L. and Bell, S. S.: Tidal influence on a fringing mangrove intertidal fish community as observed by in situ video recording: implications for studies of tidally migrating nekton, Mar. Ecol. Prog. Ser., 370, 207-219, 2008.

Falkowski, P. G. and Raven, J. A.: Aquatic photosynthesis, Malden Mass, Blackwell Science, Oxford, 375 pp., 1997.

Faunce, C. H. and Serafy, J. E.: Mangroves as fish habitat: 50 years of field studies, Mar. Ecol. Prog. Ser., 318, 1-18, 2006.

Froese, R. and Pauly, D.: Fishbase, available at: http://www. fishbase.org, last access: 4 December 2017.

Fry, F. E. J. (Eds.): The Effect of Environmental Factors on the Physiology of Fish, University of Toronto Press, Toronto, 62 pp., 1971.

Gedan, K. B., Altieri, A. H., Feller, I., Burrell, R., and Breitburg, D.: Community composition in mangrove ponds with pulsed hypoxic and acidified conditions, Ecosphere, 8, e02053, https://doi.org/10.1002/ecs2.2053, 2017.

Gleeson, J., Santos, I. R., Maher, D. T., and Golsby-Smith, L.: Groundwater-surface water exchange in a mangrove tidal creek: Evidence from natural geochemical tracers and implications for nutrient budgets, Mar. Chem., 156, 27-37, 2013.

Gregorutti, B., Michel, B., and Saint-Pierre, P.: Correlation and variable importance in random forests, Stat. Comput., 27, 659-678, 2017.

Hothorn, T., Hornik, K., and Zeileis, A.: Party: A Laboratory for Recursive Part(y)itioning, R package version 0.9-9999, available at: http://cran.r-project.org/package=party (last access: 12 March 2019), 2010

Igulu, M. M., Nagelkerken, I., Dorenbosch, M., Grol, M. G. G., and Harborne, A. R.: Mangrove habitat use by juvenile reef fish: meta-analysis reveals that tidal regime matters more than biogeographic region, PLoS ONE, 9, e114715, https://doi.org/10.1371/journal.pone.0114715, 2014.

Johnston, R. and Sheaves, M.: Small fish and crustaceans demonstrate a preference for particular small-scale habitats when mangrove forests are not accessible, J. Exp. Mar. Biol. Ecol., 353, 164-179, 2007.

Kenney, B. E., Litaker, W., Duke, C. S., and Ramus, J.: Community oxygen metabolism in a shallow tidal estuary, Estuar. Coast. Shelf Sci., 27, 33-43, 1988.

Knight, J. M., Griffin, L., Dale, P. E. R., and Sheaves, M.: Shortterm dissolved oxygen patterns in sub-tropical mangroves, Estuar. Coast. Shelf Sci., 131, 290-296, 2013.

Kramer, D. L.: Dissolved oxygen and fish behavior, Environ. Biol. Fish., 18, 81-92, 1987.

Krumme, U.: Patterns in tidal migration of fish in a Brazilian mangrove channel as revealed by a split-beam echosounder, Fish. Res., 70, 1-15, 2004.

Laroche, J., Baran, E., and Rasoanandrasana, N. B.: Temporal patterns in a fish assemblage of a semiarid mangrove zone in Madagascar, J. Fish Biol., 51, 3-20, 1997.

Lawton, J. H.: From Physiology to Population Dynamics and Communities, Funct. Ecol., 5, 155-161, 1991.

Leopold, A., Marchand, C., Deborde, J., and Allenbach, M.: Water Biogeochemistry of a Mangrove-Dominated Estuary Under a Semi-Arid Climate (New Caledonia), Estuar. Coast., 40, 773791, 2017.

Li, X. Y., Hu, B. X., Burnett, W. C., Santos, I. R., and Chanton, J. P.: Submarine Ground Water Discharge Driven by Tidal Pumping in a Heterogeneous Aquifer, Ground Water, 47, 558-568, 2009.

Marchand, C., Lallier-Vergès, E., and Allenbach, M.: Redox conditions and heavy metals distribution in mangrove forests receiving effluents from shrimp farms (Teremba Bay, New Caledonia), J. Soils Sed., 11, 529-541, 2011.

Mattone, C. and Sheaves, M.: Patterns, drivers and implications of dissolved oxygen dynamics in tropical mangrove forests, Estuar. Coast. Shelf Sci., 197, 205-213, 2017.

Mazda, Y., Sato, Y., Sawamoto, S., Yokochi, H., and Wolanski, E.: Links between physical, chemical and biological processes in Bashita-minato, a mangrove swamp in Japan, Estuar. Coast Shelf Sci., 31, 817-833, 1990.

McGill, B.J., Enquist, B.J., Weiher, E., and Westoby, M.: Rebuilding community ecology from functional traits, Trends Ecol. Evol., 21, 178-185, 2006.

Mercier, L., Darnaude, A. M., Bruguier, O., Vasconcelos, R. P., Cabral, H. N., Costa, M. J., Lara, M., Jones, D. L., and Mouillot, D.: Selecting statistical models and variable combinations for optimal classification using otolith microchemistry, Ecol. Appl., 21, 1352-1364, 2011.

Meynecke, J.-O., Poole, G. C., Werry, J., and Lee, S. Y.: Use of PIT tag and underwater video recording in assessing estuarine fish movement in a high intertidal mangrove and salt marsh creek, Estuar. Coast. Shelf Sci., 79, 168-178, 2008.

Nagelkerken, I., Roberts, C., van der Velde, G., Dorenbosch, M., van Riel, M. C., Cocheret de la Morinière, E., and Nienhuis, P.: 
How important are mangroves and seagrass beds for coral-reef fish? The nursery hypothesis tested on an island scale, Mar. Ecol. Prog. Ser., 244, 299-305, 2002.

Nagelkerken, I., Blaber, S. J. M., Bouillon, S., Green, P., Haywood, M., Kirton, L. G., Meynecke, J. O., Pawlik, J., Penrose, H. M., Sasekumar, A., and Somerfield, P. J.: The habitat function of mangroves for terrestrial and marine fauna: A review, Aquat. Bot., 89, 155-185, 2008.

Nezlin, N. P., Kamer, K., Hyde, J., and Stein, E. D.: Dissolved oxygen dynamics in a eutrophic estuary, Upper Newport Bay, California, Estuar. Coast. Shelf Sci., 82, 139-151, 2009.

Olds, A. D., Connolly, R. M., Pitt, K. A., Maxwell, P. S.: Habitat connectivity improves reserve performance, Conserv. Lett., 5, 56-63, 2012.

Peña, M. A., Katsev, S., Oguz, T., and Gilbert, D.: Modeling dissolved oxygen dynamics and hypoxia, Biogeosciences, 7, 933957, https://doi.org/10.5194/bg-7-933-2010, 2010.

Rahel, F. J. and Nutzman, J. W.: Foraging in a Lethal Environment: Fish Predation in Hypoxic Waters of a Stratified Lake, Ecology, 75, 1246-1253, 1994.

Reis-Filho, J. A., Giarrizzo, T., and Barros, F.: Tidal migration and cross-habitat movements of fish assemblage within a mangrove ecotone, Mar. Biol., 163, 1-13, 2016.

Robertson, A. I. and Duke, N. C.: Mangrove fish-communities in tropical Queensland, Australia: Spatial and temporal patterns in densities, biomass and community structure, Mar. Biol., 104, 369-379, 1990.

Rogers, N. J., Urbina, M. A., Reardon, E. E., McKenzie, D. J., and Wilsonl, R. W.: A new analysis of hypoxia tolerance in fishes using a database of critical oxygen level (Pcrit), Conserv. Physiol., 4, cow012, https://doi.org/10.1093/conphys/cow012, 2016.

Rountree, R. A. and Able, K. W.: Spatial and temporal habitat use patterns for salt marsh nekton: implications for ecological functions, Aquat. Ecol., 41, 25-45, 2007.
Sheaves, M.: Nature and consequences of biological connectivity in mangrove systems, Mar. Ecol. Prog. Ser., 302, 293-305, 2005.

Sheaves, M., Johnston, R., and Baker, R.: Use of mangroves by fish: new insights from in-forest videos, Mar. Ecol. Prog. Ser., 549, 167-182, 2016.

Shoji, J., Masuda, R., Yamashita, Y., and Tanaka, M.: Effect of low dissolved oxygen concentrations on behavior and predation rates on red sea bream Pagrus major larvae by the jellyfish Aurelia aurita and by juvenile Spanish mackerel Scomberomorus niphonius, Mar. Biol., 147, 863-868, 2005.

SHOM (Service hydrographique et oceanique de la marine): available at: https://www.shom.fr, last access: 1 March 2017.

Smith, K. J. and Able, K. W.: Dissolved oxygen dynamics in salt marsh pools and its potential impacts on fish assemblages, Mar. Ecol. Prog. Ser., 258, 223-232, 2003.

Tyler, R. M., Brady, D. C., and Targett, T. E.: Temporal and spatial dynamics of diel-cycling hypoxia in estuarine tributaries, Estuar. Coast., 32, 123-145, 2009.

Unsworth, R. K. F., Bell, J. J., and Smith, D. J.: Tidal fish connectivity of reef and sea grass habitats in the Indo-Pacific, J. Mar Biolog. Assoc. UK, 87, 1287-1296, 2007.

Unsworth, R. K. F., De Leon, P. S., Garrard, S. L., Jompa, J., and Smith, D. J.: High connectivity of Indo-Pacific seagrass fish assemblages with mangrove and coral reef habitats, Mar. Ecol. Prog. Ser., 353, 213-224, 2008.

Vaquer-Sunyer, R. and Duarte, C. M.: Thresholds of hypoxia for marine biodiversity, P. Natl. Acad. Sci. USA, 105, 15452-15457, 2008.

Wannamaker, C. M. and Rice, J. A.: Effects of hypoxia on movements and behavior of selected estuarine organisms from the southeastern United States, J. Exp. Mar. Biol. Ecol., 249, 145$163,2000$.

Wood, S. N. (Eds.): Generalized Additive Models: An Introduction With R, Chapman and Hall/CRC, Florida, 391 pp., 2007. 